\title{
Definitions, Criteria and Global Classification of Mast Cell Disorders with Special Reference to Mast Cell Activation Syndromes: A Consensus Proposal
}

\author{
Peter Valent ${ }^{\mathrm{a}, \mathrm{b}}$ Cem Akin ${ }^{\mathrm{c}}$ Michel Arock ${ }^{\mathrm{d}}$ Knut Brockow ${ }^{\mathrm{e}}$ Joseph H. Butterfield ${ }^{\mathrm{f}}$ \\ Melody C. Carter ${ }^{g}$ Mariana Castells ${ }^{c}$ Luis Escribano ${ }^{h}$ Karin Hartmann ${ }^{i}$ Philip Lieberman $^{j}$

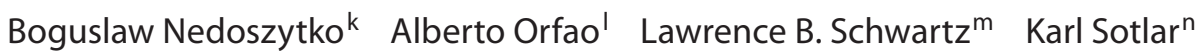 \\ Wolfgang R. Sperr ${ }^{a}$ Massimo Triggianio ${ }^{\circ}$ Rudolf Valenta ${ }^{p}$ Hans-Peter Horny ${ }^{q}$ \\ Dean D. Metcalfeg \\ a Division of Hematology and Hemostaseology, Department of Internal Medicine I, Medical University of Vienna, \\ and ${ }^{b}$ Ludwig Boltzmann Cluster Oncology, Vienna, Austria; ${ }^{c}$ Division of Rheumatology, Immunology, and \\ Allergy, Brigham and Women's Hospital, Harvard Medical School, Boston, Mass., USA; 'LBPA CNRS UMR8113, \\ Ecole Normale Supérieure de Cachan, Cachan, France; e Department of Dermatology and Allergy Biederstein, \\ Technical University of Munich, Munich, Germany; ${ }^{f}$ Division of Allergic Diseases, Mayo Clinic, Rochester, Minn., and

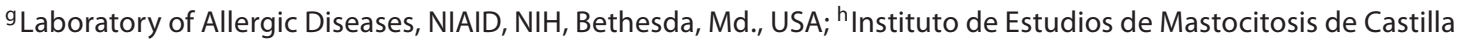 \\ La Mancha, Hospital Virgen del Valle, Toledo, Spain; 'Department of Dermatology, University of Cologne, Cologne, \\ Germany; ' Division of Allergy and Immunology, University of Tennessee, Germantown, Tenn., USA; ${ }^{2}$ Department of \\ Dermatology, Medical University of Gdansk, Gdansk, Poland; 'Servicio Central de Citometria, Centro de \\ Investigacion del Cancer (IBMCC; CSIC/USAL) and Department of Medicine, University of Salamanca, Salamanca, \\ Spain; ${ }^{m}$ Division of Rheumatology, Allergy and Immunology, Department of Internal Medicine, Virginia \\ Commonwealth University, Richmond, Va., USA; ${ }^{n}$ Institute of Pathology, Ludwig-Maximilians-University, \\ Munich, Germany; ${ }^{\circ}$ Division of Allergy and Clinical Immunology, University Federico II, Naples, Italy; ${ }^{\mathrm{P} D i v i s i o n}$ of \\ Immunopathology, Center of Physiology and Pathophysiology, Medical University of Vienna, Vienna, Austria; \\ ${ }^{\mathrm{q}}$ Institute of Pathology, Ansbach, Germany
}

\section{Key Words}

Mast cells $\cdot$ Mast cell activation syndrome $\cdot$ Allergy •

Anaphylaxis - Tryptase

\begin{abstract}
Activation of tissue mast cells (MCs) and their abnormal growth and accumulation in various organs are typically found in primary $\mathrm{MC}$ disorders also referred to as mastocytosis. However, increasing numbers of patients are now being informed that their clinical findings are due to MC activation (MCA) that is neither associated with mastocytosis nor with a defined allergic or inflammatory reaction. In other patients with MCA, MCs appear to be clonal cells, but criteria
\end{abstract}

for diagnosing mastocytosis are not met. A working conference was organized in 2010 with the aim to define criteria for diagnosing MCA and related disorders, and to propose a global unifying classification of all MC disorders and pathologic $M C$ reactions. This classification includes three types of 'MCA syndromes' (MCASs), namely primary MCAS, secondary MCAS and idiopathic MCAS. MCA is now defined by robust and generally applicable criteria, including (1) typical clinical symptoms, (2) a substantial transient increase in serum total tryptase level or an increase in other MC-derived mediators, such as histamine or prostaglandin $\mathrm{D}_{2}$, or their urinary metabolites, and (3) a response of clinical symptoms to agents that attenuate the production or activities of MC mediators. These criteria should assist in the identification

\section{KARGER}

두 2011 S. Karger AG, Basel

Fax +41613061234 E-Mail karger@karger.ch www.karger.com www.karger.com/iaa
Correspondence to: Prof. Dr. Peter Valent

Division of Hematology and Hemostaseology, Department of Internal Medicine I

Medical University of Vienna, Waehringer Guertel 18-20

AT-1090 Vienna (Austria)

Tel. +43 140400 6085, E-Mail peter.valent@ meduniwien.ac.at 
and diagnosis of patients with MCAS, and in avoiding misdiagnoses or overinterpretation of clinical symptoms in daily practice. Moreover, the MCAS concept should stimulate research in order to identify and exploit new molecular mechanisms and therapeutic targets.

Copyright $\odot 2011$ S. Karger AG, Basel

\section{Introduction}

Mast cells (MCs) are effector cells of allergic and other inflammatory reactions [1-3]. These cells originate from multilineage hematopoietic progenitors that migrate to tissues and organs where they mature and ultimately reside [2]. MCs are well known as a source of various proinflammatory mediators (table 1) and express the high-affinity IgE receptor FceRI [1-3]. Once activated by an allergen that aggregates IgEand FceRI complexes or through a number of other receptor- or non-receptor-mediated stimuli, MCs release and generate mediators that contribute to the clinical features of anaphylaxis. Clinical symptoms caused by MC activation (MCA) are among the most frequent patient complaints. Signs and symptoms range from nausea to abdominal cramping and diarrhea, from mild pruritus to anaphylaxis and life-threatening hypotension, and from tachycardia or unexplained arrhythmias to neurologic or even psychiatric symptoms $[2,4-7]$. The variability of symptoms may be explained in part by MC heterogeneity at involved organ sites, the diversity of the MC-derived mediators involved (table 1), the distribution and characteristics of triggering stimuli, local and organ-specific factors, by comorbidities, and by the magnitude of the release reaction [6-11]. Symptoms may be both acute and chronic [6-13]. An underlying allergic disorder is found in many cases [12-14]. Other underlying disorders, such as autoimmune disorders, chronic urticaria or systemic mastocytosis (SM), are less common [12-16]. However, in patients mounting severe anaphylactic reactions to hymenoptera venom both in the absence or presence of specific IgE, an underlying SM may be detected [12-20]. These patients may also suffer from 'unexplained' osteoporosis and/or gastrointestinal symptoms $[17,18]$. Other patients have similar symptoms without involvement of the MC lineage, which is important because other underlying disorders that can mimic MCA have to be considered and excluded before establishing the diagnostic checkpoint (prefinal diagnosis) of MCA.

Although MCA appears to be increasingly important in adults and children, only a few robust parameters sufficient for the documentation of such events by an objective
Table 1. MC-derived mediators considered to contribute substantially to the clinical symptoms and manifestations of MCA

\begin{tabular}{lll}
\hline Mediator & Symptom(s)/sign(s) & $\begin{array}{l}\text { Consensus } \\
\text { level }\end{array}$ \\
\hline Histamine & $\begin{array}{l}\text { headache, hypotension, urticaria } \\
\text { with or without angioedema, } \\
\text { pruritus, diarrhea }\end{array}$ & $95 \%$ \\
\hline PGD $_{2}$ & $\begin{array}{l}\text { mucus secretion, broncho- } \\
\text { constriction, vascular instability }\end{array}$ & $95 \%$ \\
\hline PAF $^{2}$ & $\begin{array}{l}\text { abdominal cramping, pulmonary } \\
\text { edema, urticaria, bronchocon- } \\
\text { striction, hypotension, arrythmia }\end{array}$ & $90 \%$ \\
\hline Proinflammatory $^{\text {cytokines }}$ & $\begin{array}{l}\text { local inflammation, edema } \\
\text { formation, leukocyte migration }\end{array}$ & $80 \%$ \\
\hline LTC 4 and LTD & $\begin{array}{l}\text { mucus secretion, edema } \\
\text { formation, vascular instability }\end{array}$ & $80 \%$ \\
\hline Chemokines & $\begin{array}{l}\text { acute inflammation and leukocyte } \\
\text { recruitment, leukocyte migration }\end{array}$ \\
\hline Tryptase & $\begin{array}{l}\text { endothelial activation with con- } \\
\text { secutive inflammatory reactions }\end{array}$ & $65 \%$ \\
\hline
\end{tabular}

PAF $=$ Platelet-activating factor; LT = leukotriene.

${ }^{1}$ Percentage of members agreeing that these mediators play a predominant role in clinical signs and symptoms recorded in patients with MCA.

${ }^{2}$ Evidence for a role of platelet-activating factor as a potential mediator of urticaria stems primarily from data obtained from healthy volunteers and in vitro studies.

approach are available, and only a few are useful for the formulation of criteria for diagnosing MCA ('MCA criteria' for short) and disease classification [21]. The current article provides a summary of consensus statements on MCA, MCA syndrome (MCAS), and diagnostic parameters by the participants of the consensus conference, together with proposed criteria and a proposed global classification of MC disorders and pathologic MC reactions.

\section{Project Description, Methods and Evaluation of Consensus Level}

In order to discuss issues raised in the community regarding MCA and to propose criteria and definitions, a Working Conference was organized in September 2010. Participating faculty members (hereinafter called 'the members') discussed current and novel diagnostic procedures, markers, criteria and algorithms in premeeting 
online discussions between September 2009 and September 2010. All members actively joined and contributed to pre- and postconference discussions and consensus sessions. The conclusions were formulated into consensus statements, the level of consensus being defined as percent agreement, i.e. the percentage of members agreeing with a given statement.

The members also set up a pilot project to explore patients' opinions. Patients and patients' organizations (mastocytosis) from the EU and US were invited to contribute by providing their opinion by answering questionnaires. Each group was coordinated by representatives of the patients' organizations and guided by members of the consensus consortium (C.A. and P.V.). The purpose of this effort was to learn about unknown or poorly recognized problems and concerns in the patient community, unmet needs, and to collect specific major suggestions.

\section{Definition and Proposed MCA Criteria}

The members agreed (unanimously) that it is of importance to define MCA using accepted, objective, easily measurable, and commonly applicable parameters and criteria. After extensive discussions, the following criteria were regarded as indicative of systemic MCA: (1) typical clinical signs and symptoms, (2) substantial and transient increase in an MC-derived mediator in biological fluids [preferred: serum total tryptase, but also histamine/histamine metabolites and prostaglandin $\mathrm{D}_{2}\left(\mathrm{PGD}_{2}\right) / \mathrm{PGD}_{2}$ urinary metabolites] during or shortly after the acute event compared to a baseline level recorded either before the acute event or at least $24 \mathrm{~h}$ after all clinical signs and symptoms of the event have completely resolved, and (3) an objective major response of clinical symptoms to agents that attenuate the production or activity of MC-derived mediators (table 2). All three criteria should be met to attribute a clinical condition to systemic MCA. However, in some circumstances, a patient may not respond to a drug and may even require intensive care and epinephrine administration. In such a patient, the condition may still be considered as MCA if typical symptoms (1) and an increase in MC mediators (2) are present, and a primary underlying MC disease (e.g. SM) or an underlying IgEmediated disease (e.g. allergy) is known. If this is not the case, other explanations for the symptoms must be ruled out. In addition, the possibility of local MCA has to be considered. The criteria for systemic MCA are specified in more detail in the following three paragraphs.
Table 2. Criteria for the diagnosis of MCA

Typical clinical symptoms (see table 3 )

Increase in serum total tryptase by at least $20 \%$ above baseline plus $2 \mathrm{ng} / \mathrm{ml}$ during or within $4 \mathrm{~h}$ after a symptomatic period

Response of clinical symptoms to histamine receptor ${ }^{1}$ blockers or 'MC-targeting' agents, e.g. cromolyn

${ }^{1}$ Histamine receptor blockers: HR1 +/- HR2 inverse agonists.

Table 3. Symptoms considered typical for MCA by the members

\begin{tabular}{ll}
\hline Symptom(s) & Consensus level \\
\hline Flushing & $95 \%$ \\
Pruritus & $90 \%$ \\
Urticaria & $85 \%$ \\
Angioedema & $75 \%$ \\
\hline Nasal congestion & $90 \%$ \\
Nasal pruritus & $90 \%$ \\
Wheezing & $70 \%$ \\
Throat swelling & $85 \%$ \\
\hline Headache & $90 \%$ \\
Hypotension & $95 \%$ \\
Diarrhea & $90 \%$
\end{tabular}

In order to count as cocriterion of MCA, these symptoms need to be recurrent or permanent, cannot be explained by other known disorders/conditions (other than MCA), and require a therapeutic intervention. Moreover, apart from these symptoms, additional clinical and laboratory criteria have to be fulfilled for the condition/reaction to be considered as MCA.

\section{Clinical Symptoms}

A number of clinical symptoms are suggestive of systemic MCA, including acute urticaria (hives), flushing, pruritus, headache, abdominal cramping, diarrhea, vomiting, respiratory symptoms and hypotension (table 3), some of which, such as urticaria, being more suggestive than others. When two or more organ systems exhibit these signs or symptoms in parallel, require therapy and are recurrent or even permanent, the likelihood of systemic MCA increases. However, the members also agreed (100\%) that none of these symptoms per se is specific for MCA and can thus only count as MCA criteria in the context of the other two MCA criteria, i.e. when MC involvement has been documented. Nevertheless, in an emergent situation where only signs and symptoms are available in 
real time, a presumptive clinical diagnosis can be made and potentially life-saving treatment initiated without asking for further criteria. Table 3 summarizes signs and symptoms the members regarded as suggestive of MCA and thus applicable as evaluation criteria of these patients. In MCA, these clinical features are considered to be induced by MC-derived mediators like histamine, leukotriene $\mathrm{C}_{4}$, or $\mathrm{PGD}_{2}$. However, some of these mediators can also be released by basophils or both cell types. Other mediators like tryptase are preferentially produced in great abundance by MCs and thus are useful as diagnostic biomarkers.

\section{Increase in Serum Tryptase Levels}

After careful consideration, the members defined what the minimal increase in serum total tryptase above baseline in a given patient should be to be accepted as evidence for systemic MCA. The generally available test (fluoroimmune enzyme assay, Phadia) is robust and provides highly reproducible results (even at low levels) in most patients $[22,23]$. It is important to state that an elevated basal tryptase level per se is not indicative of MCA and a normal basal tryptase level does not exclude MCA. Another important aspect is that in primary MC disease (mastocytosis), basal levels of total tryptase are usually elevated, one of the minor WHO criteria for SM being a basal level of tryptase $\geq 20 \mathrm{ng} / \mathrm{ml}[23,24]$. It is also noteworthy that the rise in serum tryptase during an anaphylactic event may peak 15-60 min after the onset of symptoms and then decline with a half-life of about $2 \mathrm{~h}$. As a consequence, the magnitude of MC degranulation (and the severity of anaphylaxis) will in part determine for how long serum tryptase levels will remain elevated. Thus, the timing of sample collections and the severity of the clinical event should be considered when interpreting tryptase levels $[23,24]$. Similar considerations apply to other biomarkers of MCA. After extensive discussion and review of key data (published and presented at the conference), the members agreed $(80 \%)$ that the acute serum total tryptase level should be at least $20 \%$ plus $2 \mathrm{ng} / \mathrm{ml}$ over the baseline level (of tryptase) to be indicative of MCA and thus meet this MCAS criterion (table 3). For example, if a patient has a basal serum tryptase level of $10 \mathrm{ng} / \mathrm{ml}$, the acute level should be $>14 \mathrm{ng} / \mathrm{ml}(0.2 \times 10+10+2 \mathrm{ng} / \mathrm{ml})$ to count as an MCA criterion. Although this approach seems robust, more research and prospective clinical investigations are required to validate this MCA criterion in various clinical situations. When applying this criterion, it is also important to measure the basal serum tryptase level at least $24 \mathrm{~h}$ after complete resolution of all signs and symptoms in order to (a) confirm the transient nature of the reaction and (b) reveal or exclude an elevated baseline level of tryptase $(>20 \mathrm{ng} / \mathrm{ml})$ which is highly suggestive of $\mathrm{SM}$, even in the absence of cutaneous mastocytosis (CM), and would therefore prompt further investigation.

The members also discussed whether other mediators should be considered in the evaluation of MCA. Histamine and $\mathrm{PGD}_{2}$ are also released from MCs during MCA, and may serve as biomarkers of MCA $[4,5]$. However, histamine lacks specificity, and both lack sensitivity and have preanalytical caveats [25]. Therefore, the members agreed that tryptase for now remains the preferred marker for the documentation of MCA. However, the members agreed that other parameters should be examined as available, and that such additional tests could be helpful when the tryptase test is either not available or provides an inconclusive result (e.g. only a slight increase during suspected MCA). Of these alternative biomarkers, the preferred ones are 24-hour urinary histamine metabolites, and 24-hour urinary levels of $\mathrm{PGD}_{2}$ or its metabolite $11 \beta-\mathrm{PGF}_{2 \alpha}$ [26-30]. With regard to histamine, a caveat is that basophils also produce and store this mediator, and secrete it during anaphylactic reactions. By contrast, $\mathrm{PGD}_{2}$ is not produced by basophils [31]. An unresolved question is what minimal increase in histamine or $\mathrm{PGD}_{2}$, or what increase in their metabolites would be required to be indicative of MCA. Again, more research and clinical validation of markers are required before definitive recommendations can be provided in this regard. Altogether, there is a need to further validate available biomarkers of MCA and to develop additional objective and reproducible measures for the diagnosis of MCA.

\section{Response to Therapy}

A major response of typical clinical symptoms to antimediator-type pharmacological agents should be regarded as highly suggestive of MCA. The members agreed that a response to therapy with histamine receptor 'blockers' (inverse agonists) should be taken as a diagnostic criterion. Complete response to other drugs, such as glucocorticosteroids, cromolyn, cyclooxygenase inhibitors, leukotriene receptor blockers, 5-lipoxygenase inhibitors, or antagonists of certain cytokines, may also be regarded as indirect evidence of MCA. However, many other cell types (apart from MCs) may also be influenced by these drugs, so that a response to such agents should be regarded as supportive but nonspecific, especially if the patient is resistant to histamine receptor blockers. In patients with typical symptoms, the response to antimediator-type drugs should count as an 


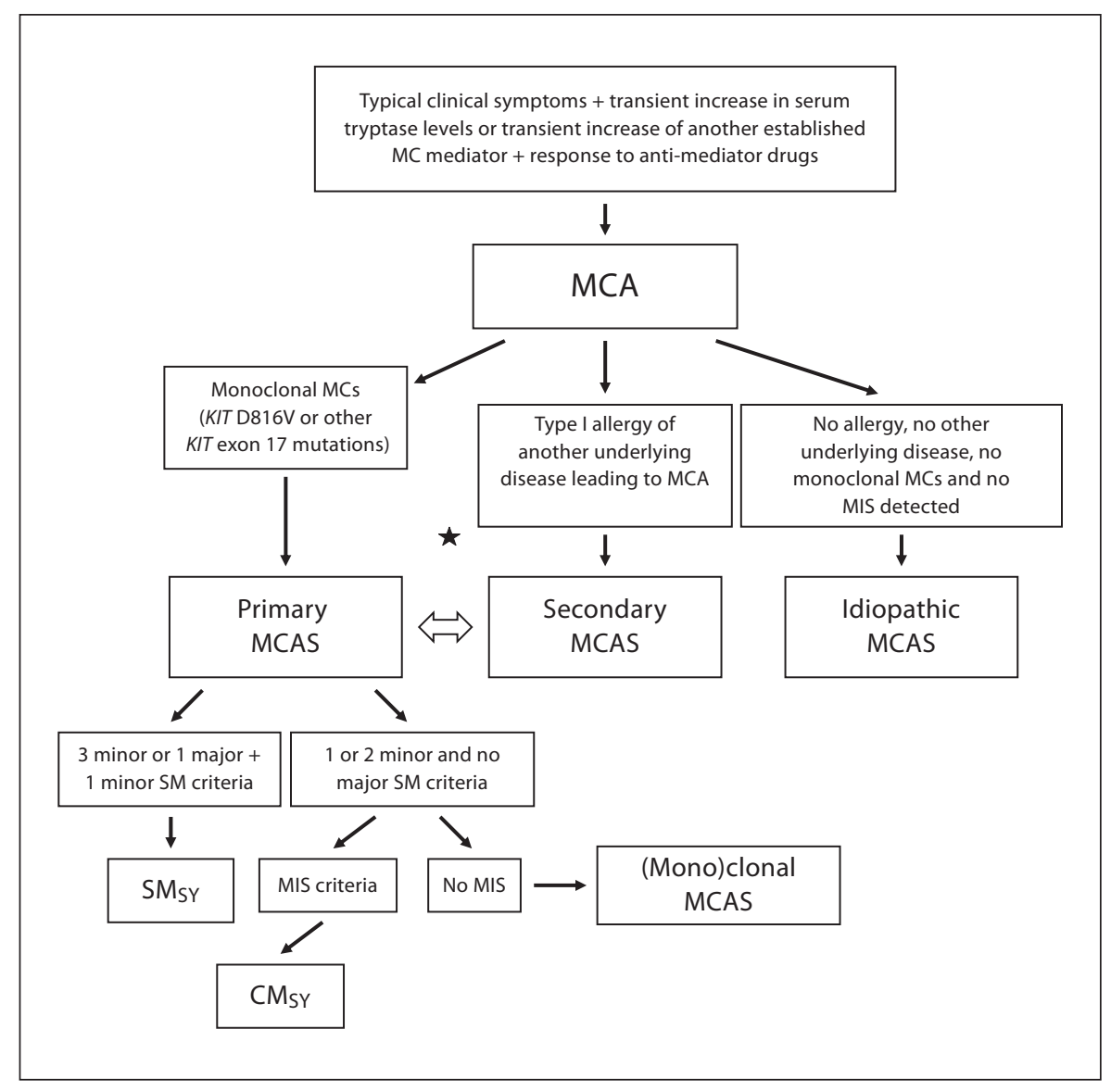

Fig. 1. Diagnostic algorithm in patients with suspected MCA disorder. In a first step, the clinical checkpoint 'MCA' has to be established by MCA criteria. Then, the patient is examined for signs and symptoms of a clonal MC disorder, i.e. the presence of (mono)clonal MCs and signs and symptoms of an underlying comorbidity that would explain MCA, such as an allergy or chronic inflammation (secondary MCA). When MC clonality is proven, the exact variant of mastocytosis needs to be defined. If only 1 or 2 minor SM criteria are found and no cutaneous involvement is detected, the final diagnosis is (mono)clonal MCAS. Note here that the KIT mutation D816V already counts as a first minor SM criterion. If no underlying disease is detected in a patient with
MCA, the final diagnosis is idiopathic MCAS. In some of the patients, the evaluation will show that both a primary MCAS and additional secondary MCAS (e.g. mastocytosis plus IgE-dependent allergy) are present (asterisk). Note that for both immunophenotyping of mast cells and KIT mutation analysis, adequate samples and methods sufficient for revealing defects in small cell numbers should be applied. With regard to KIT mutations, both the classical mutant KIT D816V, but also other KIT mutations in exon 17 should count as signs of $\mathrm{MC}$ (mono)clonality. $\mathrm{SM}_{\mathrm{SY}}=\mathrm{SM}$ with mediator-related symptoms requiring therapy, i.e. SM accompanied by primary MCA(S). MIS = Mastocytosis in the skin.
MCA criterion when a complete or major (long-lasting) resolution of symptoms according to published criteria [18] has been documented.

\section{Classification of MCAS}

The members agreed that the diagnostic algorithm proposed should include systemic MCA as a prediagnostic checkpoint, but not as a final diagnosis (fig. 1). The group agreed that, after reaching this checkpoint, subsequent studies should assess whether the patient is suffering from (1) a monoclonal MC disorder (primary MCAS), (2) allergy or another underlying disease causing MCA (secondary MCAS), or (3) idiopathic MCAS (no MC clonality and no MCA trigger identified) (fig. 1, table 4). In some patients, both (1) and (2) will apply, and (2) and (3) may sequentially occur in the same patient $[13-15,18-$ 26]. In other words, a primary MC disorder does not exclude the presence of a coexisting allergy and vice versa. 
Table 4. Classification of MCASs

\begin{tabular}{|c|c|}
\hline Category and variants & Proposed criteria \\
\hline $\begin{array}{l}\text { Primary MCAS } \\
\text { Mastocytosis } \\
\text { (Mono)clonal MCAS }\end{array}$ & $\begin{array}{l}\text { MCA criteria fulfilled and MC (mono)clonality proven } \\
(\mathrm{CD} 25+\mathrm{MCs} \text { and/or KIT D816V) }\end{array}$ \\
\hline $\begin{array}{l}\text { Secondary MCAS } \\
\text { Allergy } \\
\text { Other underlying disorder }{ }^{2}\end{array}$ & $\begin{array}{l}\text { MCA criteria fulfilled and criteria for the diagnosis of allergy or other diseases that can } \\
\text { produce MCA fulfilled as well }\end{array}$ \\
\hline Idiopathic MCAS $^{3}$ & MCA criteria fulfilled, but no disease that could lead to MCA diagnosed \\
\hline \multicolumn{2}{|c|}{$\begin{array}{l}{ }^{1} \text { CD25+ MCs plus KIT D816V detectable, or KIT D816V detectable, but MCs cannot be demonstrated to express CD25. } \\
2 \text { Disorders associated with MCA include autoimmune diseases, certain bacterial infections and some adverse drug reactions. } \\
{ }^{3} \text { Idiopathic MCAS is a final diagnosis but needs an extensive workup in order to exclude all potential underlying conditions and } \\
\text { sorders. Idiopathic and secondary MCA episodes may occur at different time points in the same patient. }\end{array}$} \\
\hline
\end{tabular}

In fact, in patients developing severe anaphylactic reactions, the possible coexistence of these two disorders must be considered. Similarly, idiopathic and secondary MCA episodes may occur at different time points in the same subject. Patients with primary MCAS can be further divided into those with true mastocytosis (by WHO criteria) and those fulfilling only one or two minor SM criteria. The latter condition can be referred to as 'monoclonal MCAS', which seems appropriate especially if KIT $\mathrm{D} 816 \mathrm{~V}$ is detected $[18,21,32,33]$. These latter patients may have a precursor or a limited form of SM, but may have the same risk of developing severe life-threatening anaphylaxis as patients with true SM. Robust criteria for the delineation and classification of mastocytosis, anaphylaxis and allergic disorders have already been published [18, 34-38] and should be applied in all patients with MCA(S). Table 4 shows an overview of categories of MCAS together with related criteria.

\section{Proposed Global Classification of MC Disorders and Pathologic MC Reactions}

The members agreed (95\%) that both mastocytosis and MCAS should be integrated into a global classification of MC-related disorders. Before discussing the proposed classification, some fundamental aspects were clarified. First, there is a natural overlap between this global classification and other classifications in internal medicine, simply because MCA is associated with the pathogenesis of a number of recognized disorders, including allergic diseases, mastocytosis, dermatologic con- ditions, and autoimmune disorders. The justification of the proposed unifying-classification approach lies in the definitive demonstration of involvement of the MC lineage, which is not provided in other classifications except for variants of mastocytosis. Second, the global classification includes neoplastic and nonneoplastic conditions, a needed extension beyond previous (WHO) classifications of MC disorders. The classification proposed by the members is shown in table 5 . This classification includes 4 major categories: MC hyperplasia, MCAS, mastocytosis, and myelomastocytic-overlap conditions.

\section{Hyperplasia}

This condition is defined by a histologically confirmed (local or systemic) increase in tissue MCs. MC hyperplasia is reactive in most cases. Independent of the organ analyzed, both KIT and tryptase should be applied as immunohistochemical markers for evaluating MC numbers [35]. In addition, multicolor flow cytometry should be used if possible. By definition, no KIT-activating mutation, no other criterion for mastocytosis (including CD2 or CD25 expression in MCs), and no signs of a myelogenous neoplasm are found. Common causes of MC hyperplasia are chronic infections, cancer, lymphoproliferative disorders, bone marrow suppression states, autoimmune disorders and other chronic inflammatory reactions. In many cases, the KIT ligand stem cell factor may be involved. In support of this conclusion, injection of recombinant stem cell factor is usually followed by local and systemic MC hyperplasia [39, 40]. MC hyperplasia can occur with or without MCA, but in most cases, no concomitant MCAS is found. 
Table 5. Global classification of MC disorders and pathologic MC reactions

\begin{tabular}{|c|c|}
\hline Proposed term & Primary definition \\
\hline Mast cell hyperplasia ${ }^{1}$ & $\begin{array}{l}\text { Increased numbers of nonclonal MCs, an underlying disease is usually found and no signs of } \\
\text { MCA are detectable; also seen in lymphoproliferative disorders and after administration of stem } \\
\text { cell factor }\end{array}$ \\
\hline Mastocytosis ( \pm MCAS) & Increased numbers of (mono)clonal MCs \\
\hline Systemic mastocytosis & SM criteria ( 3 minor or 1 major + 1 minor) met (SM variants, including MCL) \\
\hline Cutaneous mastocytosis & MIS criteria fulfilled but SM criteria not met (CM variants) \\
\hline Mastocytoma & Localized, benign, presumably (mono)clonal \\
\hline Mast cell sarcoma & Localized, aggressive (mono)clonal MCs \\
\hline Mast cell activation syndrome & MCA by the criteria listed in table 2 \\
\hline Primary MCAS & CM, SM or ‘(mono)clonal MCAS’ \\
\hline Secondary MCAS & Atopy or other disorder associated with MCA \\
\hline Idiopathic MCAS & No reason for MCA found \\
\hline Myelomastocytic conditions & MC lineage involvement in myeloid neoplasms \\
\hline Tryptase ${ }^{+}$AML & Criteria for SM or MML not met, tryptase+ blasts \\
\hline $\begin{array}{l}\text { Myelomastocytic leukemia }{ }^{2} \\
( \pm \text { MCAS) }\end{array}$ & $\begin{array}{l}\text { MC lineage involvement in MDS/AML with at least } 10 \% \text { of all cells being clonal MCs in bone } \\
\text { marrow or/and peripheral blood smears and no evidence/criteria for SM }\end{array}$ \\
\hline
\end{tabular}

${ }^{1} \mathrm{MC}$ hyperplasia is not an intrinsic MC disorder, but is a reactive state that can be seen in a wide variety of conditions, and in many instances, the clinical significance and mechanisms of MC expansion remain unclear.

${ }^{2}$ MML has not (yet) been included in the official WHO classification, although the condition is clearly defined by criteria, can clearly be discriminated from MCL and is of clinical significance because of the poor prognosis of these patients (similar to MCL but worse than other AML and MDS because of drug resistance). MIS = Mastocytosis in the skin; MDS = myelodysplastic syndrome.

\section{MCA Syndromes}

As mentioned above, MCASs are defined by the presence of MCA criteria. It is again important to emphasize that MCAS can occur as a manifestation of another MC disorder (e.g. mastocytosis: primary MCAS) or as a manifestation of an IgE-dependent disease (allergy: secondary MCAS).

\section{Mastocytosis}

In general, and as developed in previous consensus conferences, mastocytosis is divided into CM, SM, and local MC tumors (mastocytoma and MC sarcoma) [18, $34,41,42]$. CM is defined by 'mastocytosis in the skin' (MIS) criteria [18] and the absence of SM (criteria for SM not fulfilled). SM is defined by the presence of SM criteria (at least 1 major +1 minor or 3 minor WHO criteria) and may present with or without skin involvement [34]. Nevertheless, CM and SM are mutually exclusive conditions [34]. Both CM and SM may be further divided into subvariants $[18,34]$. MCA can occur in any variant of mastocytosis. In such cases, the presence of MCA(S) should be recorded as such or by the subscript 'SY', for 'symptoms' (e.g. $\left.\mathrm{SM}_{\mathrm{SY}}\right)[18,34]$.

Mast Cell Disorders: Global Classification

\section{Myelomastocytic Overlap Conditions}

Although not recognized as a subvariant by the WHO, it is important to be aware of MC lineage involvement in myeloid nonMC neoplasms [43-46]. In 30-40\% of all cases with acute myeloid leukemia (AML), some myeloblasts express tryptase (tryptase ${ }^{+}$AML) [45]. In some of these cases, myeloblasts also produce histamine [45]. However, patients with tryptase ${ }^{+}$AML usually have no signs or symptoms of MCA. Myelomastocytic leukemia (MML) is an extremely rare disease $[44,46]$. In contrast to tryptase ${ }^{+}$ AML, a significant number of neoplastic cells $(\geq 10 \%$ in blood or bone marrow smears) are immature MCs [44]. Similar to SM or MC leukemia (MCL), MML presents with an elevated basal serum tryptase level and can present with MCA. However, in contrast to SM and MCL, the criteria for diagnosing SM are not fulfilled $[44,46]$. Most cases of MML are misdiagnosed as basophilic leukemia, MCL, acute promyelocytic leukemia, tryptase ${ }^{+} \mathrm{AML}$, or $\mathrm{SM}$ with an associated hematologic nonMC lineage disease (SM-AHNMD). Similar to MCL, the prognosis in MML is poor $[43,44,46]$. As mentioned above, the basal serum tryptase level is elevated in MML. However, this is not a specific feature as leukemic blasts and (neoplastic) basophils also express and release tryptase $[47,48]$.

Int Arch Allergy Immunol 2012;157:215-225 


\section{Impact of Pathology, Genetics and Molecular Markers}

The classification proposed above is seen by the members as a logical extension of previous proposals to classify MC disorders, including the WHO classification [41, 42]. However, several questions remain concerning diagnostic parameters and assays, and the mechanisms of MCA. Likewise, it remains open whether all patients with MCA should have a bone marrow examination to establish the MCAS variant, or only those whose basal tryptase level is elevated (or exceeds $20 \mathrm{ng} / \mathrm{ml}$ ), or only those who are at risk based on the recently proposed score of the Spanish Network of Mastocytosis (REMA score), which is predictive of MC clonality and includes gender, absence of urticaria or angioedema, presence of syncope or presyncope and tryptase levels [13]. It also remains open what molecular defects and markers, apart from activating KIT mutations at codon 816 and other activating KIT exon 17 mutations [49], might be indicative of a primary MCAS. Recent studies have shown that a number of additional activating KIT mutations may be detected in $\mathrm{CM}$, although a clear association with the pathogenesis of the disease often remains uncertain (apart from KIT D816V) [50]. In addition, germline single-nucleotide polymorphisms and other somatic mutations may contribute to MCA or may augment or counteract KIT-dependent MCA. Other single-nucleotide polymorphisms may contribute to the evolution (progression) of an underlying MC disorder [51, 52].

The members agreed that research should focus on the identification of such novel genetic defects and establish whether they are associated with the pathogenesis. Further, the clinical impact of such lesions and their applicability as criteria in the future need to be considered on a 'case-by-case' basis. Other molecular parameters and gene array features may improve diagnostic approaches and assist in the delineation of SM, underlying immunologic diseases and various allergic disorders presenting with MCA.

\section{Impact of the Classification on Research and Practice}

The major advantage of our newly proposed criteria, algorithm and classification may be that misdiagnosis and overinterpretation of MCA in clinical practice can be avoided, with positive implications for patients, physicians and for the health care system (including economic aspects). For example, patients with poorly defined symptoms are sometimes diagnosed with MCA without a solid diagnostic basis. Such patients may suffer from an unrelated disease that is then overlooked. The members of the consortium considered it of utmost importance to apply solid diagnostic criteria in all such patients in order to avoid time- and cost-consuming evaluations and establish the correct diagnosis.

\section{Differential Diagnoses}

When the criteria for MCA are not met, other underlying diseases that explain symptoms should be pursued. This is crucial as such conditions may cause continuous problems or may even be life-threatening. Common conditions that may be confused with MCA include cardiovascular disorders (e.g. in patients with hypotension and shock), certain endocrine disorders, diverse neoplasms, gastrointestinal diseases, primary skin diseases, various infectious diseases and neurologic or psychiatric conditions. It is important to explore these alternative diagnoses carefully and to record all symptoms and laboratory parameters that may help the physician to arrive at the correct conclusion. Serum tryptase as well as other available MC biomarkers should be determined in these patients. If such values are normal, they should be repeated in the follow-up if symptoms occur. If histamine or histamine metabolite levels increase during an attack, but tryptase levels remain consistently normal, the condition may be related to basophil activation or a histamine-secreting (carcinoid) tumor. Even in patients in whom no (systemic) increase in any mediator can be documented, the possibility remains that local tissue-based symptoms result from basophil activation and/or MCA within these tissues. However, such a scenario is unlikely to result in systemic symptoms, and local consequences of MC release, such as urticaria, angioedema, rhinitis and asthma, are obvious. Additionally, local MC degranulation within inflammatory reactions such as inflammatory bowel disease has been reported but should not be taken as evidence that the pathology is primarily MC dependent. These considerations should be kept in mind when a patient has typical symptoms (table 3 ) and is responding well to cromolyn, whose cell target(s) and mechanism(s) of action are nonspecific [53]. A special differential diagnosis is histamine intoxication following ingestion of histamine or its metabolites, which may be present, for instance, in wine, seafood, fish or soy sauce [54]. Another condition that has been reported is histamine intolerance, which has been 
Table 6. Top 10 issues raised by patients in the US and EU

\begin{tabular}{|c|c|}
\hline US & EU \\
\hline $\begin{array}{l}\text { 1. Better access to care from physicians knowledgeable } \\
\text { in MC disorders and more specialized centers }\end{array}$ & $\begin{array}{l}\text { 1. Improved knowledge of all doctors in various disciplines } \\
\text { relevant to MC disorders }\end{array}$ \\
\hline $\begin{array}{l}\text { 2. Definitions and criteria for MCAS (clonal and nonclonal } \\
\text { variants) }\end{array}$ & 2. ID card for all patients and countries in Europe \\
\hline 3. Curative rather than symptomatic therapy & 3. New better therapeutic agents \\
\hline $\begin{array}{l}\text { 4. Education and awareness of physicians and health care } \\
\text { professionals in recognition of symptoms of MC disorders }\end{array}$ & 4. More specialized centers in various countries in the EU \\
\hline $\begin{array}{l}\text { 5. Practice parameters of diagnosis and therapy incorporating } \\
\text { commonly available methods }\end{array}$ & $\begin{array}{l}\text { 5. Improved knowledge and definition of mediator-associated } \\
\text { symptoms }\end{array}$ \\
\hline 6. Better access to and assistance in obtaining medications & 6. More mastocytosis specialists \\
\hline $\begin{array}{l}\text { 7. More recognition of gastrointestinal manifestations of MC } \\
\text { diseases }\end{array}$ & 7. Improved diagnostic methods \\
\hline $\begin{array}{l}\text { 8. Better holistic care plans to address symptoms such as } \\
\text { anaphylaxis, fatigue, bone pain, brain fog, pain and } \\
\text { neuropsychiatric symptoms }\end{array}$ & 8. More information to patients \\
\hline 9. More research into familial occurrence & $\begin{array}{l}\text { 9. Further development of existing classifications of MC } \\
\text { disorders }\end{array}$ \\
\hline $\begin{array}{l}\text { 10. New treatment options for cutaneous disease, aggressive SM } \\
\text { and MCL }\end{array}$ & $\begin{array}{l}\text { 10. More information to patients via commonly accessible } \\
\text { media }\end{array}$ \\
\hline
\end{tabular}

The two reports (EU and US) were prepared independently by using documented material provided by the patients' organizations, and with assistance by 2 faculty members.

suggested to result from an abnormal histamine metabolism $[55,56]$. It remains unknown whether these patients indeed react inappropriately to small quantities of histamine or may suffer from an increased level of endogenous or exogenous histamine. Interestingly, some of these patients turn out to have SM when basal tryptase levels are measured and found to be elevated - and then, a bone marrow examination needs to be performed.

\section{Open Questions and Issues Raised by Patients}

Although definitions and criteria for MCA and mastocytosis are presented within this consensus document and should assist in daily practice, questions remain. Likewise, physicians are often unsure about the diagnosis of SM or confuse SM with other medical disorders. In other cases, MCAS is diagnosed without proper examination and documentation. In order to explore the patients' views on these questions, we completed two pilot projects with an identical setup, one in the US and one in the EU. In this project, many of the urgent issues and suggestions were formulated and listed by patients. The two projects were conducted under the guidance of members of the consensus group (C.A. in the US and P.V. in the EU). The 10 top important proposals are listed in table 6 . As expected for a rare disease, the patients' wish is to increase the number of reference and referral centers and expert physicians in the EU and US. Other important issues to be solved by the community are to develop more effective therapies for the various categories of the disease, and to extend general awareness and knowledge on disease variants. Patients' opinions and suggestions were presented in detail to the members at the consensus conference, and there was unanimous recognition that the academic community is appreciative of this initiative, and that the patients' suggestions are to be considered in forthcoming projects and network activities. The European Competence Network on Mastocytosis (ECNM) [57] and similar initiatives in the US will continue to assume a leading role in efforts to address these issues and concerns, preferably in cooperation projects and concerted actions.

\section{Concluding Remarks and Future Perspectives}

The MC lineage is involved in diverse pathologic reactions and medical disorders. The spectrum of related clinical symptoms and pathologies is broad. As a consequence, disorders attributed primarily to MCA need clear 
diagnostic criteria to prevent under and overdiagnoses. During the past two decades, robust criteria for various MC disorders and reactions have been defined by consensus groups. In the current article, our consensus group has extended its project to the definition of MCA and MCAS, with solid criteria and now presents a proposal for a global classification of pathologic MC reactions and MC disorders. These criteria and definitions should assist in daily practice, in the preparation and conduct of clinical trials, and in the formulation of basic science approaches and translational research in the future. Of immediate importance is that these novel criteria and definitions, if applied routinely, should be helpful in establishing correct diagnoses, and in avoiding misdiagnoses and overinterpretations of findings and symptoms.

\section{Acknowledgements}

We would like to thank the following persons for providing support and assistance in logistic and administrative or technical issues of the conference: Kordula Krassel, Sabine Sonnleitner, Sa- bine Cerny-Reiterer, Emir Hadzijusufovic, Harald Herrmann and Friedrich Wimazal, who also contributed by voting. We would also like to thank the patients' organizations in the US and EU for their contributions and support in this project. This research was supported in part by the Intramural Research Program of the NIH, NIAID, by the Ministerio de Sanidad y Asuntos Sociales (FIS PS09/00032) Fondo de Investigación Sanitaria de Castilla la Mancha (FISCAM 2007/36 and FISCAM 2008/46); the Fonds zur Förderung der Wissenschaftlichen Forschung in Österreich, and a Mastocytosis Grant of the Medical University of Vienna, Austria.

\section{Contributions}

All persons listed as coauthors actively participated as Faculty Members in the 2010 Working Conference on Mast Cell Disorders, in Pre- and Postconference Discussions, in the Consensus Voting, and in preparing and writing the Consensus Manuscript. All coauthors approved the final version of the document. Data presented in table 6 were prepared and approved by representatives of patients' organizations in the US and EU, and released for publication in the present paper.

\section{References}

1 Rivera J, Gilfillan AM: Molecular regulation of mast cell activation. J Allergy Clin Immunol 2006;117:1214-1225.

-2 Metcalfe DD: Mast cells and mastocytosis. Blood 2008;112:946-956.

3 Galli SJ, Grimbaldeston M, Tsai M: Immunomodulatory mast cells: negative, as well as positive, regulators of immunity. Nat Rev Immunol 2008;8:478-486.

4 Austen KF: Systemic anaphylaxis in the human being. N Engl J Med 1974;291:661-664.

5 Serafin WE, Austen KF: Mediators of immediate hypersensitivity reactions. $\mathrm{N}$ Engl J Med 1987;317:30-34.

-6 Simons FE: Anaphylaxis. J Allergy Clin Immunol 2010;125:S161-S181.

7 Webb LM, Lieberman P: Anaphylaxis: a review of 601 cases. Ann Allergy Asthma Immunol 2006;97:39-43.

-8 Lieberman P: Epidemiology of anaphylaxis. Curr Opin Allergy Clin Immunol 2008;8: 316-320.

-9 Peavy RD, Metcalfe DD: Understanding the mechanisms of anaphylaxis. Curr Opin Allergy Clin Immunol 2008;8:310-315.

10 Golden DB: What is anaphylaxis? Curr Opin Allergy Clin Immunol 2007;7:331-336.

11 Finkelman FD, Boyce JA, Vercelli D, Rothenberg ME: Key advances in mechanisms of asthma, allergy, and immunology in 2009. J Allergy Clin Immunol 2010;125:312-318.
12 Metcalfe DD: Differential diagnosis of the patient with unexplained flushing/anaphylaxis. Allergy Asthma Proc 2000;21:2124.

-13 Alvarez-Twose I, González de Olano D, Sánchez-Muñoz L, Matito A, Esteban-López MI Vega $\mathrm{A}$, et al: Clinical, biological, and molecular characteristics of clonal mast cell disorders presenting with systemic mast cell activation symptoms. J Allergy Clin Immunol 2010;125:1269.e.2-1278.e2.

14 González de Olano D, de la Hoz Caballer B, Núñez López R, Sánchez Muñoz L, Cuevas Agustín M, Diéguez MC, Alvarez Twose I, Castells MC, Escribano Mora L: Prevalence of allergy and anaphylactic symptoms in 210 adult and pediatric patients with mastocytosis in Spain: a study of the Spanish network on mastocytosis (REMA). Clin Exp Allergy 2007;37:1547-1555.

15 Bonadonna P, Perbellini O, Passalacqua G, Caruso B, Colarossi S, Dal Fior D, Castellani L, Bonetto C, Frattini F, Dama A, Martinelli G, Chilosi M, Senna G, Pizzolo G, Zanotti R: Clonal mast cell disorders in patients with systemic reactions to Hymenoptera stings and increased serum tryptase levels. J Allergy Clin Immunol 2009;123:680-686.

16 Metcalfe DD, Schwartz LB: Assessing anaphylactic risk? Consider mast cell clonality. J Allergy Clin Immunol 2009;123:687-688.
17 Donker ML, Bakker NA, Jaspers WJ, Verhage AH: Two patients with osteoporosis: initial presentation of systemic mastocytosis. J Bone Miner Metab 2008;26:199-202.

18 Valent P, Akin C, Escribano L, Fodinger M, Hartman K, Metcalfe DD, et al: Standards and standardization in mastocytosis: consensus statement on diagnostics, treatment recommendations and response criteria. Eur J Clin Invest 2007;37:435-453.

19 Ruëff F, Dugas-Breit S, Przybilla B: Stinging Hymenoptera and mastocytosis. Curr Opin Allergy Clin Immunol 2009;9:338-342.

20 Akin C: Anaphylaxis and mast cell disease: what is the risk? Curr Allergy Asthma Rep 2010;10:34-38.

21 Akin C, Valent P, Metcalfe DD: Mast cell activation syndrome: proposed diagnostic criteria. J Allergy Clin Immunol 2010;126: 1099-1104

22 Schwartz LB, Bradford TR, Rouse C, Irani AM, Rasp G, Van der Zwan JK, Van der Linden PW: Development of a new, more sensitive immunoassay for human tryptase: use in systemic anaphylaxis. J Clin Immunol 1994; 14:190-204.

23 Schwartz LB, Sakai K, Bradford TR, Ren S, Zweiman B, Worobec AS, Metcalfe DD: The alpha form of human tryptase is the predominant type present in blood at baseline in normal subjects and is elevated in those with systemic mastocytosis. J Clin Invest 1995;96: 2702-2710. 
24 Schwartz LB, Irani AM: Serum tryptase and the laboratory diagnosis of systemic mastocytosis. Hematol Oncol Clin North Am 2000;14:641-657.

25 Morel AM, Delaage MA: Immunoanalysis of histamine through a novel chemical derivatization. J Allergy Clin Immunol 1988; 82:646-654.

26 Awad JA, Morrow JD, Roberts LJ: Detection of the major urinary metabolite of prostaglandin $\mathrm{D}_{2}$ in the circulation: demonstration of elevated levels in patients with disorders of systemic mast cell activation. J Allergy Clin Immunol 1994;93:817-824.

27 Hogan AD, Schwartz LB: Markers of mast cell degranulation. Methods 1997;13:43-52.

28 Di Lorenzo G, Pacor ML, Vignola AM, Profita M, Esposito-Pellitteri M, Biasi D, Corrocher R, Caruso C: Urinary metabolites of histamine and leukotrienes before and after placebo-controlled challenge with ASA and food additives in chronic urticaria patients. Allergy 2002;57:1180-1186.

29 van Toorenenbergen AW, Oranje AP: Comparison of serum tryptase and urine $\mathrm{N}$-methylhistamine in patients with suspected mastocytosis. Clin Chim Acta 2005;359:72-77.

-30 Butterfield JH, Weiler CR: Prevention of mast cell activation disorder-associated clinical sequelae of excessive prostaglandin $D_{2}$ production. Int Arch Allergy Immunol 2008; 147:338-343.

- 31 van der Donk EM, Blok W, Kok PT, Bruijnzeel PL: Leukotriene $\mathrm{C}_{4}$ formation by enriched human basophil preparations from normal and asthmatic subjects. Prostaglandins Leukot Essent Fatty Acids 1991;44:11-17.

- 32 Sonneck K, Florian S, Müllauer L, Wimazal F, Födinger M, Sperr WR, Valent P: Diagnostic and subdiagnostic accumulation of mast cells in the bone marrow of patients with anaphylaxis: monoclonal mast cell activation syndrome. Int Arch Allergy Immunol 2007;142:158-164.

- 33 Akin C, Scott LM, Kocabas CN, KushnirSukhov N, Brittain E, Noel P, Metcalfe DD: Demonstration of an aberrant mast-cell population with clonal markers in a subset of patients with 'idiopathic' anaphylaxis. Blood 2007;110:2331-2333.

- 34 Valent P, Horny HP, Escribano L, Longley BJ, Li CY, Schwartz LB, Marone G, Nuñez R, Akin C, Sotlar K, Sperr WR, Wolff K, Brunning RD, Parwaresch RM, Austen KF, Lennert K, Metcalfe DD, Vardiman JW, Bennett JM: Diagnostic criteria and classification of mastocytosis: a consensus proposal. Leuk Res 2001;25:603-625.

35 Horny HP, Valent P: Diagnosis of mastocytosis: general histopathological aspects, morphological criteria, and immunohistochemical findings. Leuk Res 2001;25:543551.

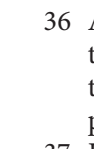

6 Arock M, Valent P: Pathogenesis, classification and treatment of mastocytosis: state of the art in 2010 and future perspectives. Expert Rev Hematol 2010;3:497-516.

37 Johansson SG, Bieber T, Dahl R, Friedmann PS, Lanier BQ, Lockey RF, Motala C, Ortega Martell JA, Platts-Mills TA, Ring J, Thien F, Van Cauwenberge P, Williams HC: Revised nomenclature for allergy for global use: report of the Nomenclature Review Committee of the World Allergy Organization, October 2003. J Allergy Clin Immunol 2004;113: 832-836.

38 Sampson HA, Muñoz-Furlong A, Campbell RL, Adkinson NF Jr, Bock SA, Branum A, et al: Second symposium on the definition and management of anaphylaxis: summary report - Second National Institute of Allergy and Infectious Disease/Food Allergy and Anaphylaxis Network symposium. J Allergy Clin Immunol 2006;117:391-397.

- 39 Costa JJ, Demetri GD, Harrist TJ, Dvorak AM, Hayes DF, Merica EA, et al: Recombinant human stem cell factor (kit ligand) promotes human mast cell and melanocyte hyperplasia and functional activation in vivo. J Exp Med 1996;183:2681-2686.

40 Jordan JH, Schernthaner GH, Fritsche-Polanz R, Sperr WR, Födinger M, Chott A, et al: Stem cell factor-induced bone marrow mast cell hyperplasia mimicking systemic mastocytosis (SM): histopathologic and morphologic evaluation with special reference to recently established SM-criteria. Leuk Lymphoma 2002;43:575-582.

41 Valent P, Horny H-P, Li CY, Longley JB, Metcalfe DD, Parwaresch RM, Bennett JM: Mastocytosis; in Jaffe ES, Harris NL, Stein H, Vardiman JW (eds): World Health Organization (WHO) Classification of Tumours. Pathology and Genetics. Tumours of Haematopoietic and Lymphoid Tissues.Lyon, IARC Press, 2001, pp 291-302.

42 Horny HP, Akin C, Metcalfe DD, Escribano L, Bennett JM, Valent P, Bain BJ: Mastocytosis (mast cell disease); in Swerdlow, SH, Campo E, Harris NL, Jaffe ES, Pileri SA, Stein H, Thiele J, Vardiman JW (eds): World Health Organization (WHO) Classification of Tumours. Pathology and Genetics. Tumours of Haematopoietic and Lymphoid Tissues. Lyon, IARC Press, 2008, pp 54-63.

43 Valent P, Sperr WR, Samorapoompichit P, Geissler K, Lechner K, Horny HP, Bennett JM: Myelomastocytic overlap syndromes: biology, criteria, and relationship to mastocytosis. Leuk Res 2001;25:595-602.

44 Valent P, Samorapoompichit P, Sperr WR, Horny HP, Lechner K: Myelomastocytic leukemia: myeloid neoplasm characterized by partial differentiation of mast cell-lineage cells. Hematol J 2002;3:90-94.

$\checkmark 45$ Sperr WR, Jordan JH, Baghestanian M, Kiener HP, Samorapoompichit P, Semper H, et al: Expression of mast cell tryptase by myeloblasts in a group of patients with acute myeloid leukemia. Blood 2001;98:2200-2209.
46 Arredondo AR, Gotlib J, Shier L, Medeiros B, Wong K, Cherry A, et al: Myelomastocytic leukemia versus mast cell leukemia versus systemic mastocytosis associated with acute myeloid leukemia: a diagnostic challenge. Am J Hematol 2010;85:600-606.

47 Castells MC, Irani AM, Schwartz LB: Evaluation of human peripheral blood leukocytes for mast cell tryptase. J Immunol 1987;138: 2184-2189.

48 Samorapoompichit P, Kiener HP, Schernthaner GH, Jordan JH, Agis H, Wimazal F, et al: Detection of tryptase in cytoplasmic granules of basophils in patients with chronic myeloid leukemia and other myeloid neoplasms. Blood 2001;98:2580-2583.

49 Garcia-Montero AC, Jara-Acevedo M, Teodosio C, Sanchez ML, Nunez R, Prados A, et al: KIT mutation in mast cells and other bone marrow hematopoietic cell lineages in systemic mast cell disorders: a prospective study of the Spanish Network on Mastocytosis (REMA) in a series of 113 patients. Blood 2006;108:2366-2372.

50 Bodemer C, Hermine O, Palmérini F, Yang Y, Grandpeix-Guyodo C, Leventhal PS, et al: Pediatric mastocytosis is a clonal disease associated with D816V and other activating cKIT mutations. J Invest Dermatol 2010;130: 804-815.

51 Daley T, Metcalfe DD, Akin C: Association of the Q576R polymorphism in the interleukin-4 receptor $\alpha$-chain with indolent mastocytosis limited to the skin. Blood 2001;98: 880-882.

52 Nedoszytko B, Niedoszytko M, Lange M, van Doormaal J, Gleń J, Zabłotna $M$, et al: Interleukin-13 promoter gene polymorphism $-1112 \mathrm{C} / \mathrm{T}$ is associated with the systemic form of mastocytosis. Allergy 2009;64: 287-294.

53 Murphy S, Kelly HW: Cromolyn sodium: a review of mechanisms and clinical use in asthma. Drug Intell Clin Pharm 1987;21:2235.

54 Chin KW, Garriga MM, Metcalfe DD: The histamine content of oriental foods. Food Chem Toxicol 1989;27:283-287.

55 Maintz L, Novak N: Histamine and histamine intolerance. Am J Clin Nutr 2007;85: 1185-1196.

56 Schwelberger HG: Histamine intolerance: a metabolic disease? Inflamm Res 2010;59: 219-221.

57 Valent P, Arock M, Bischoff SC, Bühring HJ, Brockow K, Escribano L, et al: The European Competence Network on Mastocytosis (ECNM). Wien Klin Wochenschr 2004;116: 647-651.

58 Vadas P, Gold M, Perelman B, Liss GM, Lack G, Blyth T, et al: Platelet-activating factor, PAF acetylhydrolase, and severe anaphylaxis. N Engl J Med 2008;358:28-35. 